\title{
Balancing Risk Prevention and Health Promotion: Towards a Harmonizing Approach in Care for Older People in the Community
}

\author{
Bienke M. Janssen • Tine Van Regenmortel • \\ Tineke A. Abma
}

Published online: 7 January 2012

(C) The Author(s) 2012. This article is published with open access at Springerlink.com

\begin{abstract}
Many older people in western countries express a desire to live independently and stay in control of their lives for as long as possible in spite of the afflictions that may accompany old age. Consequently, older people require care at home and additional support. In some care situations, tension and ambiguity may arise between professionals and clients whose views on risk prevention or health promotion may differ. Following Antonovsky's salutogenic framework, different perspectives between professionals and clients on the pathways that lead to health promotion might lead to mechanisms that explain the origin of these tensions and how they may ultimately lead to reduced responsiveness of older clients to engage in care. This is illustrated with a case study of an older woman living in the community, Mrs Jansen, and her health and social care professionals. The study shows that despite good intentions, engagement, clear division of tasks and tailored care, the responsiveness to receive care can indeed not always be taken for granted. We conclude that to harmonize differences in perspectives between professionals and older people, attention should be given to the way older people endow meaning to the demanding circumstances they encounter (comprehensibility), their perceived
\end{abstract}

B. M. Janssen $(\bowtie) \cdot$ T. Van Regenmortel

Department of Social Studies, Fontys University of Applied Sciences, P.O. Box 347, 5600 AH

Eindhoven, The Netherlands

e-mail: bienke.janssen@fontys.nl

T. Van Regenmortel

e-mail: t.vanregenmortel@fontys.nl

T. Van Regenmortel

Faculty of Social Sciences and Research Institute for Labour and Society (HIVA),

Catholic University Leuven, Parkstraat 47, 5300, 3000 Leuven, Belgium

T. A. Abma

Department of Medical Humanities, EMGO Institute, VU Medical Center, Van der Boechorststraat 7 , 1081 BT Amsterdam, The Netherlands

e-mail: t.abma@vumc.nl 
feelings of control (manageability), as well as their motivation to comprehend and manage events (meaningfulness). Therefore, it is important that both clients and professionals have an open mind and attempt to understand each others' perspective, and have a dialogue with each other, taking the life narrative of clients into account.

Keywords Health promotion - Risk prevention - Narratives - Older people · Salutogenesis - Sense of coherence

\section{Introduction}

Ageing is associated with increased reliance on health-related and support services $[10,14]$. Old age often goes hand in hand with increasingly complex and often interrelated problems, encompassing physical, psychological and social health [42]. Older people also tend to have higher rates of chronic illness such as diabetes, heart disease or disabilities associated with stroke. Moreover, by 2040 some 80 million people worldwide will suffer from dementia [16]. Despite these problems, the majority of older people in Europe continue to live in their own home, and numbers are expected to rise in the near future [18, 32].

Many shortcomings have recently been observed in elderly care, such as problems related to the coordination and continuation of care [10] as well as to the early detection and diagnosis of problems [19]. Another problem is that not all older people are responsive to the care offered to them $[3,5,45]$, and that there is a wide variety in the effectiveness of different health promotion activities [11]. This raises the question as to how to provide care for this expanding group of vulnerable older people and how to promote their health and wellbeing. In the Netherlands for example, answers are sought in screening instruments and new organization models, such as chain care [46].

The purpose of this article is to describe different pathways to health promotion and to explain how a difference in focus between professionals and clients may lead to tension and ambiguity in the care process, and may ultimately result in reduced responsiveness of clients to engage in a (tailored) care plan.

To illustrate this, we will use a case study that was selected for many reasons, including its ambiguities and therefore its learning potential. The case study involves Mrs Jansen and her health and social care professionals. Aged 79, and living in the community, Mrs Jansen is in need of long-term professional care. Her story is based on in-depth interviews with herself and her caregivers, and on participant observations performed during a number of geriatric team meetings during which Mrs Jansen was frequently discussed. These interviews and observations were part of a larger study on the quality of care for older people living in the community in the Netherlands.

Antonovsky's framework [6-8], helps us understand the mechanisms that lead to the ambiguities and tensions in Mrs Jansen's care process, and gives an indication of how to minimize or prevent these ambiguities between older people, caregivers and others. 
The first part of this article examines two major directions to health promotion and their influence on the choices care professionals make in the care for older people. After describing the study and the contextual background, we illustrate these influences taking Mrs Jansen's case as an example. The last part of this article reflects on what this case teaches us about health promotion for older people living in the community.

\section{Typology of Health Promotion}

The World Health Organization [41] suggests that: "Health promotion is the process of enabling people to increase control over, and to improve their health".

Health promotion aims to enable people to address health problems and lead healthier lives.

Ewles and Simnett [15] distinguish five approaches to health promotion, each necessitating the use of different kinds of activities. These approaches are: medical; behavioural change; educational; client-centred, and societal change. These approaches are described in Table 1.

These tried and tested approaches are effective, yet they are not without a number of limitations. One of the most important criticisms is that health promotion often adopts a deficit/pathogenic driven approach that over-relies on risk, rather than putting the emphasis on protective mechanisms [7, 8, 31, 34]. In other words these approaches focus on the failure of individuals and local communities to avoid disease rather than on their potential to create and sustain health and continued development [28]. Whiting and Miller [40] therefore suggest a sixth, complementary approach for health promotion that gives prominence to people's health needs. This approach has been strongly influenced by the previous work of Aaron Antonovsky [6-8], and conceptually differs from disease prevention strategies [21, 36]. Antonovsky states that the pathogenic paradigm leads to diminished power when understanding and dealing with chronic illness, as follows: "one must reject the image of specific pathogen disease and apply the concept of multiple causation" [8]. He alternatively developed his salutogenic approach as complementary to pathogenic approaches [9, 28]. This approach essentially grew out of Antonovsky's concern that a different paradigm was required in order to conduct health research. It must be stated that, in practice, different approaches can be combined; they are not mutually exclusive and, as with all typologies, boundaries are blurred.

\section{Salutogenic Approach}

Antonovsky's research [6] focuses on identifying general resources that individuals use to manage the tension associated with stressors. Salutogenic approaches imply a focus on health maintenance processes rather than on disease processes. Table 2 summarizes the perspectives and assumptions of the pathogenic and salutogenic approaches to health promotion according to Antonovsky [7].

Antonovsky believed that developing and maintaining health is important since it gives a person the potential to have the opportunity and the ability to move towards the life he or she wants [9]. Care professionals in a salutogenic approach should ask 
Table 1 Health prevention approaches described by Ewles and Simnett [15]

\section{Medical approach:}

The medical approach aims to enable people to be free from medically defined disease and disability, such as infectious diseases, cancer and heart disease. The approach involves medical interventions to prevent or ameliorate ill health. Possibly using a persuasive paternalistic method, persuading for example middle age people to be screened for high blood pressure. This approach values preventive medical procedures and the medical profession's responsibility to ensure that patients comply with recommended procedures

\section{Behavioral change approach:}

The behavioral change approach is based upon changing people's individual attitudes and behaviors so that they adopt a "healthy lifestyle". Examples include teaching people how to stop smoking, look after their teeth, eat the "right food", and so on. In this approach it is argued that a healthy lifestyle is in the best interest of individuals and health professionals promoting this approach will see it as their responsibility to encourage as many people as possible to adopt the healthy lifestyle they advocate

\section{Educational approach:}

The aim of the education approach is to provide individuals with information, ensure knowledge and understanding of health issues, and to enable well-informed decisions to be made. Information about health is presented, and people are helped to explore their values and attitudes and to make their own decisions. Help in carrying out those decisions and adopting new health practices may also be offered. The educational approach encourages individuals to make their own decisions and at the same time health professionals will see it as their responsibility to raise with clients the health issues which they think will be in the client's best interests

Client centered approach:

Within the client centered approach the health professional works with clients to help them identify what they want to know about and take action on, and make their own decisions and choices according to their own interests and values. The role of the health professional is to act as a facilitator. They help people to identify their concerns and gain the knowledge and skills they require making changes happen. Self-empowerment of the client is seen as central. Clients are valued as equals. They have knowledge, skills and abilities to contribute, and they have an absolute right to control their own health destinies

\section{Societal change approach:}

Rather than changing the behavior of individuals, the societal change approach modifies the physical and social environment in order to make it more conducive to good health. Those using this approach will value their democratic right to change society, and will be committed to putting health on the political agenda at all levels and to the importance of shaping the health environment instead of shaping the individual lives of people who live in it

questions such as: "How can people be helped to move toward greater health?" [8], and: "What are the forces that lead people to grow old healthily and can lead to 'good adaptation' to age-dependent changes" [43]. Antonovsky believes that asking these kinds of questions forces professionals to consider all the factors in a person's life that affect their health, and to look at a person's overall state of health and illness [7, 8, 23]. Antonovsky promoted a Sense Of Coherence (SOC) as a path to better health. He defined a SOC as:

A global orientation that expresses the extent to which one has a pervasive, enduring though dynamic feeling of confidence that (1) the stimuli deriving from one's internal and external environments in the course of living are structured, predictable and explicable; (2) the resources are available to one to 
Table 2 Perspectives and assumptions of the pathogenic and the salutogenic paradigm; the five fundamental questions as described by Antonovsky [7]

\begin{tabular}{|c|c|c|}
\hline Question & Pathogenic paradigm & Salutogenic paradigm \\
\hline $\begin{array}{l}\text { How are people } \\
\text { classified in terms } \\
\text { of health status? }\end{array}$ & $\begin{array}{l}\text { Dichotomous classification: People } \\
\text { are classified as either healthy or } \\
\text { sick }\end{array}$ & $\begin{array}{l}\text { As a continuum: Total health and total } \\
\text { illness are the extreme poles. Humans are } \\
\text { all partly healthy and partly sick }\end{array}$ \\
\hline $\begin{array}{l}\text { What is to be } \\
\text { understood and } \\
\text { treated? }\end{array}$ & $\begin{array}{l}\text { Focus of attention is on the } \\
\text { scientific diagnosis of the } \\
\text { specific disease of the patient }\end{array}$ & $\begin{array}{l}\text { Focus of attention is on the assessment of } \\
\text { the overall state of the health/illness of a } \\
\text { person }\end{array}$ \\
\hline $\begin{array}{l}\text { What are the } \\
\text { important } \\
\text { etiological factors? }\end{array}$ & $\begin{array}{l}\text { Focus on the risk factors for a } \\
\text { particular disease being } \\
\text { considered } \\
\text { Starting point: disease or problem }\end{array}$ & $\begin{array}{l}\text { Focus on the total story of a person which } \\
\text { can explain location on the continuum of } \\
\text { health and disease, including salutary, } \\
\text { health promoting resources } \\
\text { Starting point: health potential }\end{array}$ \\
\hline $\begin{array}{r}\text { How are stressors } \\
\text { conceptualized? }\end{array}$ & $\begin{array}{l}\text { A stressor is conceptualized as } \\
\text { somewhat unusual and } \\
\text { pathogenic } \\
\text { (Chain: stressor-stress-disease) } \\
\text { Disease or infirmity as an anomaly }\end{array}$ & $\begin{array}{l}\text { A stressor is conceptualized as ubiquitous } \\
\text { (inherent in human existence) and open } \\
\text { ended in consequences. A stressor such } \\
\text { as divorce might, for example, turn out to } \\
\text { have positive effects for someone's } \\
\text { wellbeing } \\
\text { Humans are flawed and subject to entropy }\end{array}$ \\
\hline $\begin{array}{l}\text { How is suffering to } \\
\text { be treated? }\end{array}$ & $\begin{array}{l}\text { By starting "a war against disease" } \\
\text { React to signs, symptoms and } \\
\text { indications of disease }\end{array}$ & $\begin{array}{l}\text { By strengthening coping resources } \\
\text { Create conditions of physical, mental and } \\
\text { social well-being }\end{array}$ \\
\hline
\end{tabular}

meet the demands posed by these stimuli; and (3) these demands are challenges, worthy of investment and engagement [6, p. 19].

In his formulation, the sense of coherence has three components:

- Comprehensibility: a belief that things happen in an orderly and predictable fashion and a sense that you can understand events in your life and reasonably predict what will happen in the future.

- Manageability: a belief that you have the skills or ability, the support, the help, or the resources necessary to take care of things, and that things are manageable and within your control.

- Meaningfulness: a belief that things in life are interesting and a source of satisfaction, that things are really worth it and that there is good reason or purpose to care about what happens.

Antonovsky's SOC refers to three different components in a path to better health: the way people endow meaning to the stressful or demanding circumstances they encounter (comprehensibility); their perceived feelings of control (manageability); and their motivation to comprehend and manage events (meaningfulness). According to Antonovsky, the third element is the most important. If a person believes there is no reason to persist and survive and confront challenges or if they have no sense of meaning, then they will have no motivation to comprehend and manage events. His essential argument is that "salutogenesis" depends on 
experiencing a strong "sense of coherence". Research shows that perceptions that life's challenges are worth facing decrease with age [12]. Moreover, older people, particularly those living alone, should be supported to maintain a high sense of coherence throughout their life span because they appear to be at risk of a decreased sense of coherence, which negatively affects their perceived wellbeing [12, 17].

Before we present Mrs Jansen's case history we first explain more about the contextual background and the methodology of our study.

\section{Contextual Background}

The research was conducted in a medium-sized city in the Netherlands $(103,000$ inhabitants).

A healthcare centre that provides care and social services to six diverse neighbourhoods is located in the heart of the research area. The residents in these neighbourhoods are a mix, but the socio-economic status of most of them is relatively low. Thirty percent of them are 55 or older, and five percent are 80 or older.

The healthcare centre is run by various healthcare professionals and social workers and liaises with other health and social care organizations such as homecare, general practices, social work and intramural care in order to provide integrated services for older people in the community. In 2000, the healthcare centre and its affiliated local health and social care organizations developed an approach for integrated, person-centred care for older people living in their working area: the multidisciplinary geriatric team approach. This multidisciplinary geriatric team discuss older people living in the community who have complex, often multiple problems and an extensive need for care. Multiple problems are defined as problems in the following areas: physical, social and mental health, financial situation, living situation, and safety. The members of the team work out a tailored care plan that best meets the needs of the older person it concerns. The plan is based on three main principles: Firstly, it must aim at the social inclusion of older people. Secondly, it should be preventive and pro-active. Thirdly, it should aim to provide individual support for older people in need of care and family members who provide care.

During the meetings, team members can nominate older people with multiple problems and/or impairments. If an older person is to be considered, then a number of topics are discussed: age, living situation, the number of care providers already involved, the strengths, and the impairments the older person has to cope with, the quality of the person's informal network, and the reason why this particular the case was nominated in the meeting, including the question to the other participants.

The case is then discussed in depth, and a professional is appointed to coordinate the case. Minutes of meetings are taken so that progress can be carefully monitored, a process that continues until a case is closed. Clients are asked permission for their case to be discussed in the meetings. Meetings are held once a month, and the care providers who attend are always the same irrespective of which older people are discussed. However, other professionals are asked to attend the meetings if this is 
desirable. Measures are taken to guarantee the privacy of the older person under discussion.

The team started with thirteen health and social care professionals involved in geriatric care in the same working area (i.e. primary and secondary care, health and social care, institutional and care provided in the community).

One social professional from a welfare organization eventually left the geriatric team meetings due to a lack of time. The remaining twelve professionals are: a general practitioner, four nurse practitioners, two homecare nurses, one homecare worker, two case managers, one nursing home manager, and a certified professional consultant on ageing. All the professionals have been on the geriatric team from its inception.

General practitioners in the Netherlands are the gatekeepers to specialized care. More than half Dutch general practices have nurse practitioners [13] who perform diagnostic tests e.g. lung measurements, assess clients' health and living condition and go on (preventive) social visits, and coordinate client care (liaison between general practice and other health services) [24, 25]. Nurse practitioners in some general practices are also responsible for providing (social) care for older people living in the community. This is the case in the general practices involved in this study. The case managers are employed by organizations that provide intramural care for older people (i.e. nursing home care). When older people are placed on the waiting list for such homes, the case managers are responsible for the care and support at home until the care recipient is actually admitted to a nursing home. In most cases this concerns older people with dementia.

\section{Methodology}

The case study [33] presented here was part of an empirical study to investigate the perspectives, experiences and approaches of health and social care professionals and their clients [27]. A combination of methods was used, referred to as datatriangulation [20]. The notes, recordings and transcripts of the multidisciplinary geriatric team meetings were used, as were in-depth interviews with care professionals and some of their care recipients, notes taken during informal meetings, the details of phone calls, e-mails, and internal documents, such as the project descriptions.

Participant observations were conducted for one and a half years (December 2006-July 2008) in the multidisciplinary geriatric team. The first author observed 16 meetings $(16 \mathrm{~h})$. These 16 meetings discussed a total of 42 cases. The observer's role involved watching, listening and having informal conversations with team members before and after the meetings. Participants were also allowed to initiate discussions. The observations helped us understand, among other things, the process of decision and sense making. The observations were combined with in-depth interviews with all twelve members of the multidisciplinary team. These interviews started with an open question: what is it like working with older people living in the community? Topics included: daily working activities, style of approaching work, contact with the older people, and the working environment. The interviews took 
about $1 \mathrm{~h}$. In addition to the professionals, we (first author) also interviewed a number of older people in need of care $(n=30)$ with whom we came into contact through the members of the geriatric team. These findings have been published elsewhere [22]. Some of these respondents $(n=7)$, including Mrs Jansen, were discussed during the multidisciplinary meetings.

The framework for the interviews with the older people living in the community was fairly open, which facilitated focused, conversational two-way communication. The majority of questions were created during the interview, giving both the interviewer and the interviewee sufficient flexibility to probe for details or discuss certain issues. Among other things, they were asked about what happened when they became dependent on health and care services and to what extent they encountered any difficulties that had had a negative impact on their wellbeing and identity. The interviews were structured by using an interview guide which defined the topics to be covered: the interviewee's own situation, their search for help, experiences with health and social care services, experiences when interacting with care professionals and informal carers, and coping strategies. The interviewer only used this guide to check whether all the important topics mentioned above were discussed. There was also sufficient opportunity during the interview to discuss issues that emerged during the conversation. Furthermore, an attempt was made to create a comfortable, conversational atmosphere. The interviews with the older people were held in their own homes and lasted about $2 \mathrm{~h}$.

The researchers obtained written informed consent from the members of the team and oral informed consent from the older people for them to be included in this study.

This article focuses on a single case study. We were interested in selecting a case that enabled us to understand the perspective of the professionals and that of the care recipient. Seven cases were available that had interview data from both parties and field notes taken at the geriatric meetings. Mrs Jansen's case was selected because, among other reasons, she was frequently discussed during the meetings. As she was a complex person in a complex situation, Mrs Jansen occupied the minds of the health and social care professionals involved. Despite the individual package of support that was specifically designed for her situation and the value she attaches to contact with some of her professionals, Mrs Jansen was not willing to accept some forms of help, and was critical of the role other professionals played in her case. Given these ambiguities the case has a 'high learning potential', one of the selection criteria for selecting a case in line with an intrinsic case study approach [33], the aim of which is to unravel the particularities of a case, and to understand it from an insider's perspective.

The geriatric team meetings and the interviews were recorded, transcribed verbatim, and subjected to narrative analysis [29, 30]. The content, narrative structure (plots, key moments in the care process) and linguistic elements (discourse, metaphors) were part of the analysis. To stay as close to the meanings of the respondents as possible we conducted member checks [26]. In our case we sat down with Mrs Jansen to discuss our findings. Furthermore we included three evaluation moments in which the first results of the analysis of the data were discussed with the participating professionals. Lastly, the main results of the 
analysis of the case were sent to the care professionals involved in Mrs Jansen's case. They were asked whether they recognized the results of the analysis and to respond if this was not the case. None of the professionals disagreed with the content of the summary.

The reliability of the findings was enhanced because the analysis of the case study was regularly and systematically discussed by the three research team members. Possible differences in perspectives were discussed until agreement about the analysis was reached. This verification strategy is known as "inter-rated reliability" [27].

\section{Case Example}

The story of Mrs Jansen (pseudonym) and her health and social care professionals is presented below.

\section{Mrs Jansen}

Mrs Jansen, 79 years old, lives alone in an apartment near the centre of a city in the Netherlands. As the youngest daughter in a large family she stayed at home in her youth to help her mother with the household. She married when she was eighteen. Mrs Jansen had seven children and mainly took care of the household. She expresses positive feelings and thoughts about her past in which she experienced what it was "to work hard".

Ten years ago her beloved husband died. This was a difficult time in her life. Not only because of her loss, but also because he had done those tasks in the household, such as their financial administration, which, because she was illiterate, were not easy tasks for her to do. She admits that this was one of the reasons her alcohol consumption increased, something for which she was later treated in an alcohol rehabilitation centre. The intentions of the professionals in this rehabilitation centre were good, but Mrs Jansen experienced her stay as "worse than being in jail". She observes: "These professionals were vermin; they all thought they knew what was best for me". Against the advice of her children and the professionals, she left the rehabilitation centre before finishing her treatment. She is open about the fact that she still sometimes finds it difficult to resist alcohol.

Mrs Jansen's health has gradually declined over the past few years. Two years ago she lost her footing and broke a hip. Since then she has used a rolling walker. More recently she suffered internal bleeding and was admitted to hospital. Mrs Jansen currently fills her days doing the domestic chores she is still able to do (e.g. washing up, doing the laundry), watching television and smoking cigarettes. Although she says she "can't complain" about her life at the moment, she does admit to still missing her husband everyday:

There's no one to say "good morning" or "good night" to you, and you have to sit on your own at the dinner table, that's not always very nice. (...) When 
we were together we often went for a walk or played cards. When you're alone you don't do these kinds of things anymore.

Mrs Jansen is strongly motivated to take care of herself. Staying active by, for instance, doing her domestic chores, and the privacy of her own home are what she values most. Being in her own home means she can spend her days any way she wants to: "In my own home I can sit, I can lie down and walk around the way I want". She is proud of the fact that although she does not have a lot of money, she does not have any serious financial problems. She allows her children and the certified professional consultant on ageing to help her maintain this situation. It is important for her that she is financially independent of her children. One of her daughters lives nearby and helps her withdraw cash, and go shopping.

When asked about her near future Mrs Jansen explains she lives from day to day and will take the future as it comes:

I don't want to think about my future and about what might happen to me. If you think about these things, you'll see it happen. (..) And if things happen, I'll see then.

\section{The Care Process}

Because of problems Mrs Jansen encounters in different areas of her life (health, cognitive, financial, and social), various health and social care professionals and organizations are involved with her. The certified professional consultant on ageing helps Mrs Jansen with her financial administration, among other things; homecare workers pay her a daily visit to help with her housekeeping and assist in her personal care; and a nurse practitioner sees her for a regular medical check-up and a chat. All the professionals involved have known her for a very long time, since she has been a client of the local healthcare centre for a long period of time.

Because Mr Jansen was in need of care, contact with the couple intensified just before he passed away. After his death, the professionals kept in contact with Mrs Jansen.

\section{Professional Perspectives}

The health and social professionals acknowledged that Mrs Jansen was in need of professional care. They had various reasons for nominating her in their meetings. Their three major concerns in her current situation were: (1) safety at home; Mrs. Jansen has difficulty walking so there is always a risk she might fall. Her medical history concerns the health and social health professionals. They are afraid that something might happen to her while she is alone in her apartment and they feel responsible for her. (2) performing daily activities (ADL); besides needing help with dressing, taking a shower and performing some domestic tasks, the professionals involved indicated that Mrs Jansen also has problems with her medication and she often takes too many pills. As this might have serious consequences for her health, the health and social care professionals believe something needs to be done about it. 
(3) Her frequent consumption of alcohol (and to a lesser extent her smoking); Mrs Jansen's lifestyle is also cause for concern. Her drinking and smoking are, they agree, not beneficial for her health. One of the care professionals observed:

We think she's drinking a lot again. We have reason to believe she fell again last week, probably because she was drunk.

The professionals were open and willing to engage in Mrs Jansen's situation. Some of them were involved with her even before her husband died, and as a result they have built up a supportive relationship with her. They mentioned in particular that one of Mrs Jansen's daughters was important for her as she lives nearby and is very attentive to her mother. They have discussed with her children how to divide tasks between them. One of the social care professionals was appointed to keep in regular contact with Mrs Jansen's children, and to discuss things with them.

During the meetings the health and social care professionals talked about how to deal with Mrs Jansen's situation. Over time the following health promotion activities were discussed:

- The professionals thought that Mrs Jansen would be well advised to apply for a room in a residential home. In the meantime the care professionals indicated that it was wise get Mrs Jansen to go to the day-care centre in her neighbourhood. They reasoned that the centre was a good option for her as it provided her with useful day activities, structure and social contact.

- Besides the relocation option, the health and social care professionals took steps to make Mrs Jansen's home as safe as possible for her. To this end, they talked about her lifestyle (smoking, drinking) and agreed that this was not helping her mental and physical condition. They believed it was important to "objectivize her medical condition". Different medical tests were proposed to achieve this.

- The amount of homecare on offer needed to be increased to help Mrs Jansen with her day to day activities. This could only done through a standardized assessment procedure conducted by a government agency.

- The professionals decided that Mrs Jansen could best be helped with her medication if the pharmacist were to deliver her medication on a daily basis so that it would be much easier for her to take the right amount.

- Two activities were planned to deal with her excessive drinking habits. Firstly, the professionals believed it important that there was no alcohol in her apartment and therefore no-one should buy alcohol for her-neither the health professionals nor her children. It was also suggested that Mrs Jansen be introduced to a social worker specialized in alcohol addiction with a view to her situation being assessed.

The team members knew each other very well, and they had been familiar with Mrs Jansen's particular situation for a number of years. As a result, communication between the professionals was good. Clear agreements were made during the meetings, and responsibilities allocated. All the professionals involved knew what was expected of them and all accepted their responsibility. In fact, all the activities were carried out in the end as planned. 
Mrs Jansen's Wishes and Expectations

However, it emerged during the care-giving process that Mrs Jansen had her own specific wishes and expectations. On the one hand she admitted to being satisfied and happy with the regular visits from the certified professional consultant on ageing and the nurse practitioners, and she appreciated their expertise. She identifies with them and describes this as follows:

They're nice people. They help me. I always ask them if they want some coffee. They are ordinary people, just like me.

Mrs Jansen realizes, for example, that it is difficult for her to take care of her own finances, and therefore she relies on the certified professional consultant on ageing to help her achieve her goal of "not getting into debt".

On the other hand she is more critical about other professionals and activities that were arranged for her. There are two critical moments in her case that involve the tailored care plan offered to her. This is when the care activities offered to her do not seem to link up with Mrs Jansen's expectations and wishes. As a result she is not responsive to these care activities.

The first critical moment in the care process was when Mrs Jansen was strongly urged to move from her apartment, and a room was found for her in a residential home. She was willing for one of the professionals to accompany her to go and see the home and the room that was available, but was reluctant when it came to agreeing to a move. As Mrs Jansen says:

Once they've showered me and I'm dressed, there's nothing else for me to do in a residential home. I don't want to go to there.

Relocation for Mrs Jansen would mean an unwelcome change to her daily routine and diminished vitality and lust for life: "I'd rather be lying in the ground", she explains. She does not believe that moving would be good for her wellbeing. She therefore does not feel the need to mediate anything in her current living situation, and although she is aware of the risks of living alone, she explains:

If I lose my footing I'll just get back on my feet again, or I'll just wait for someone to come along.

Mrs Jansen prefers to talk about the advantages of staying in her own home and lists the resources to make that possible: microwave meals instead of cooking from scratch; not being in debt; being able, to some extent, to clean her home herself; the help she receives from her daughter and homecare etc. The professionals are more focused on reducing the specific risk factors in Mrs Jansen's life and stress the reasons why, they believe, her situation will only deteriorate in the future.

The second critical moment is when the professionals attempt to help Mrs Jansen with her excessive drinking. Although clear agreements were made not to buy alcohol for Mrs Jansen, homecare workers discovered empty bottles of alcohol in her apartment. The geriatric team professionals discussed this situation at one of their meetings: 
Professional 1: "How on earth she gets the drink, I don't know".

Professional 2: "Oh, it's not that difficult, you just call any old liquor store and they come and bring it to her. She's got the money in her home".

Mrs Jansen is open about the fact that whenever she wants a drink, she does indeed just call the liquor store and then hides the bottles from the professionals and her children. She explains:

I'm not going to torment myself. If I feel the need to drink, then I'll just buy it.

In the first instance Mrs Jansen allowed the social worker specialized in addiction to come into her home, but as a result of her former negative experience with the rehabilitation centre, Mrs Jansen did not intend to cooperate with her. Mrs Jansen said to the certified professional consultant on ageing:

If I had known that lady was going to start talking about alcohol, I wouldn't have let her in.

It was no longer possible for the social worker to visit Mrs Jansen again.

Although a few activities the professionals undertook met with some success, they still felt unable to come to grips with Mrs Jansen's situation. By the end of the research period Mrs Jansen was still living in her own home, without control and the professionals continue to be worried about "what may happen". They felt there was not much more they could do for her as she was not willing to accept the support the professionals believed she needed. After a few meetings one of the professionals in the geriatric team said:

There are some things you just don't have to bother organizing for her anymore (...) we've made so many attempts.

The professionals decide to put the situation on the back burner and "keep their eyes wide open". As a result some of the health professionals describe Mrs Jansen as someone who "determines her own course".

\section{Critical Reflection}

We showed in Mrs Jansen's case that the care professionals had good intentions, felt responsible for her, and acted in her best interest. However, instead of being responsive to this care and receptive to being involved in the tailored care plan, Mrs Jansen was critical and reserved. Her expectations appear to conflict with those of her care professionals. It is important in these kinds of situations to find out what the specific reasons are for a client to remain reluctant and at a distance [39]. Antonovsky's Sense of Coherence might be a helpful framework for unravelling this conflict.

\section{Comprehensibility}

In the two critical moments described above, the meaning Mrs Jansen and her professionals endow to risk or demanding circumstances appear to differ. 
Mrs Jansen, for example, explains that when she loses her footing she will get back on her feet again, or just wait for someone to come along. This remark indicates that she regards the risk of losing her footing as an acceptable and inherent part of her life as an older woman living alone, rather than as a factor that might make her ill. Moreover, by indicating "she is not going to torment herself" whenever she feels the urge to drink, it seems the focus of her attention is not on the consequences drinking might pose for her health.

However, the starting point for the professionals is to reduce risks or problems, which is an important part of their remit. Most of their actions focus on creating a safe environment for Mrs Jansen and helping her to unlearn her unhealthy behaviour such as her alcohol consumption and her excessive use of medication. This difference in focus on the same subject might lead to misunderstanding and conflict between Mrs Jansen and her professionals.

\section{Manageability}

The professionals and Mrs Jansen seem to differ most in how they perceive the way Mrs Jansen is in control of her situation.

Although Mrs Jansen is aware of the risks of living alone in her apartment, she believes she has the skills, abilities, support and resources available to handle her situation and to remain in her own home. She prefers to stress the positive aspects rather than identify problems for which solutions need to be found. In concrete terms, coping with these risks, for example, would mean her buying ready-made microwave meals so she would not be using gas. She also sees accepting help from her daughter and professionals in her day to day activities as a solution.

Yet the professionals doubt whether Mrs Jansen is actually able to remain in control of her situation. They are worried about "what may happen". Their tailored care plan therefore focuses primarily on managing Mrs Jansen. For example they increase the level of support for her, and try to diminish the risk factors in her life by, for example, offering her a room in a residential home, or helping her manage her need for alcohol.

\section{Meaningfulness}

Some professionals saw the fact that Mrs Jansen was not particularly interested in all the care offered to her as a "problem" and as a refusal to accept help. It can, however, also be interpreted as a strategic solution to the problems the tailored care plan pose for her identity and the meaning she attaches to her life. In her eyes, moving to a residential home for example would deprive her of the opportunity and ability to move towards the life she wants. She describes herself as a woman who has always worked hard, and appreciates the privacy and freedom of her own home. In her eyes moving to a residential home would force her to lead a passive life. She believes that if she were no longer allowed to take care of herself and her household, her life condition would deteriorate as would her satisfaction with life. Mrs Jansen says she would lose her lust for life and would "rather be lying in the ground" if she had to move to a residential home. Although she had already lost her footing a 
number of times, she reasons that her life would lose its meaning as soon as she were forced to move to a home. It is difficult for the care professionals to integrate Mrs Jansen's perspective in their tailored care plan.

Mrs Jansen admits to appreciating the fact that she is financially independent of her children and that she does not have to live with debt. She is motivated to maintain this situation. Although she has learned how to live thriftily, she knows she is not capable of managing her finances alone. She is happy that both her certified professional consultant on ageing and her daughter help her with this. This might explain why Mrs Jansen is willing to accept help here.

\section{Consequences for Care Professionals}

The analysis of the story of Mrs Jansen has implications for the provision of care. In the second critical moment, when the social health professionals responded to her level of alcohol consumption, they decided to use a behavioural change approach (see Table 1) to help her control her drinking habit. They saw it as their responsibility to encourage Mrs Jansen to adopt the healthy lifestyle they were advocating. The reasonable hypothesis behind this behavioural change model was that she would be committed to the behaviour recommended by the professionals. However, this was not the case. Again, it is important to establish the reason for her refusal. Antonovsky's sense of coherence might be useful here. Mrs Jansen might not fully understand the consequences of her drinking habit or she might believe that any negative effects of her drinking habit would not happen to her (comprehensibility). She may also not believe she has the skills, ability, support, help or resources available to handle her drinking habit (manageability), or she might not even see a reason or purpose to understand or manage her drinking habit (meaningfulness). All her arguments relate to the different forms of intervention for professionals tailored to the needs and perspectives of the individual client.

\section{Discussion}

Although the professionals in Mrs Jansen's case had good intentions, were engaged in her situation and offered her tailored care, it turned out she was not responsive to all the care offered to her. Tronto $[37,38]$ states that evaluating how care is received is an inherent and important phase in the provision of "good care". She states that insights into the mechanisms that underlie responsiveness to care are essential in order to optimally adjust care to the needs of clients. Mrs Jansen's case demonstrates that her reluctance to accept care might be explained by the difference in the pathways to health promotion. While Mrs Jansen focused on her strengths, the professionals were focused on risk prevention. This difference in pathways to health promotion can create misunderstanding, conflict and tension in the care process. The care professionals assume that Mrs Jansen does not seem to be sufficiently aware of the risks that are an inherent part of her life; they believe she should be aware of these risks and take them into account. The professionals' concerns for Mrs Jansen 
are real and sincere. At the time Mrs Jansen is not focused on these risks, and she doubts whether the professionals' intentions are sincere. Mrs Jansen feels that the professionals do not really understand her qualities, skills, motivations and aspirations. From a salutogenic point of view, this might be explained by the overreliance of the care professionals on the pathogenic factors professionals generally have towards the life of vulnerable (older) people. Professionals could have respected and paid more attention to the strategies Mrs Jansen used in order to maintain control over her current life and situation. The perspectives of both professionals and their clients should be taken into account when designing individual care packages and evaluating care. This is an ongoing process and requires an open mindset from all stakeholders involved. All these stakeholders must be willing to listen to each other and acknowledge each others' perspectives. Only then can a more balanced, mutually designed perspective on care be developed, and any conflicting perspectives in a care situation resolved.

This balanced approach between both pathways can also be related to the approach to ethics as described by Aristotle. He claimed that "moral decisions are not a product of instrumental reasoning (techne), calculation or logic (episteme) but flow from wise judgement, perceptiveness, imaginative understanding and an engagement with practice (phronenis)" [4, p. 3]. Aristotle also states that it is the dialectic between the detailed circumstances of the actual case and the general principles that foster morally right action. Other aspects that, according to Aristotle, foster this morally right action are to prohibit extreme standpoints and the use of the abovementioned phronesis or "practical wisdom" to establish what is needed in a particular situation. Following Aristotle we argue that professionals who solely focus on risks and who are not receptive or open to people's strengths are not balanced in their care approach to older people. A middle position seeks to find the right balance between preventing risks and promoting health. Aristotle teaches us that where this exact balance is to be found cannot be predefined in general terms. Each time, depending on the particulars of the situation (person, time, location etc.), professionals have to search afresh for the middle ground.

The pathogenic approach still continues to dominate elderly care. In order to reach a better balance between risk prevention and health promotion we agree with Wiesmann and Hannich [43] and Becker et al. [9] that the salutogenic approach should have a more central place in care for older people living in the community. While one approach is not more important than the other; both are needed to facilitate the goal of better health and a safer and more health-enhancing environment. Whereas professionals who opt for a pathogenic approach aim to improve health by diminishing illness and infirmity, salutogenic approaches aim to enhance health by improving physical, mental and social wellbeing. These strategies can be made to work together to create an environment that nurtures, supports, and facilitates optimal wellbeing [9].

Although research suggests that the different approaches to and strategies for improving health and preventing illness might more or less lead to the same or similar results [35], both approaches imply a different attitude from professionals. In a salutogenic approach, professionals should ask themselves what useful qualities, skills, motivation and aspirations their clients have, as these psychological resources 
are demonstrated to have a mediating role in subjective wellbeing [44]. This requires a strict and accurate accounting of clients' assets [31]. However, the discussion continues as to whether people in need of care are always inquisitive and totally attentive to and aware of their health needs. For example, it is highly likely in Mrs Jansen's case that she overestimates her skills that are needed to live independently, and that she does not have a realistic view of the seriousness of her situation. Following a hermeneutic approach to ethics, we emphasize the dialogical nature of human beings and as a consequence we point to the necessity of intersubjective decision making; morally right action arises from dialogue among open-minded people in practice [4]. This underlines the importance of professionals listening carefully to the life narrative of older people and to discuss differences in insight between older people and their professionals in an open dialogue. This dialogue must take account of the perspective of the older people, and at the same time professionals should encourage these older people to incorporate new behaviours that professionals believe are essential to maintaining and enhancing older people's health.

Our case study also raises a number of important questions about the hypotheses behind the different approaches to promoting health in older people, such as: Is it in all situations prudent to take measures to limit the risks that accompany human life? Are people in all situations committed to behaviour that is recommended by health and social care professionals? To what extent are older people inquisitive and attentive to their own health needs? Sometimes interaction patterns remain intact, reinforcing the status quo and the image of older people as being docile and silent. The salutogenic approach creates opportunities to redefine situations, thereby leading to new dynamics.

Another discussion point is what policymakers can learn from this study.

We unravelled the unique characteristics of a particular case, and we did this from the insider perspective of the participants. Stake [33] refers to an intrinsic case, and he indicates such cases can provide a context to develop realistic algorithms and hence evaluation criteria [1]. Knowledge from this case study is therefore concrete, contextual and open for different interpretations and therefore fits in the natural ways in which people assimilate information and arrive at an understanding. By describing and analysing fundamental conflicts and dilemmas as experienced by the participants and reflecting on it with the aid of existing theory, it does become possible to develop ideas about how to improve practice. In our case study, for example, the reflection contributed towards understanding the mechanisms underlying a reduced sense of responsiveness to care among older clients. We feel that being aware of differences in interpretations and values between professionals and older people is the first step towards bringing these perspectives more into harmony. What we can learn from this case is that sharing mutual expectations may diminish tension and ambiguity, and might possibly improve a client's responsiveness to care. Antonovsky's sense of coherence might serve as a tool for professionals to understand the salutogenic factors within and around their clients, and might help them adjust their care more to their clients' values and perspectives. Stories like Mrs Jansen's may help us gain a deeper understanding of exactly how tension and ambiguities in the care process originate and give us indications of how to deal with 
them. This requires an open mind (and phronesis) from both professionals and clients.

\section{Study Limitations}

Mrs Jansen's story was an intrinsic case study [33]. We wanted to illuminate the particularities of one case (Mrs Jansen). This particular case was chosen for its learning potential; it was perhaps an atypical case-Mrs Jansen has clear ideas of what she does and does not want, perseveres in these ideas and dares to question elements of the tailored care plan designed by the care professionals. But it was a case from which we could learn a great deal about the care process. It was a rich case full of ambiguities.

One possible shortcoming of this study is the internal validity of the case presented here: to what extent can the results of this study be adequately interpreted and to what extent can we have faith in these interpretations? Introducing the notion of credibility as a quality criterion gives an insight into the question of internal validity. Credibility means that the researchers acknowledge their roles as interpreters: they do not reveal some truth or other, but actively construct and endow meaning to interview data. In order to stay close to the meanings of the respondents a member check is a useful strategy [27]. In the study presented here, the analyses were discussed with the health and care professionals involved.

Another quality procedure we used is data-triangulation: we combined data collection methods in order to help broaden the scope of the data [20].

Another critique of case studies is that they would not be suitable for making generalizations and developing theory. It is however important to see the uniqueness of a local situation, which enables us to portray complexity and give a holistic impression of the situation [2]. Thick descriptions of cases may foster the naturalistic generalization of insights drawn from the studies and translated to the reader's own context.

\section{Conclusion}

The case described in this article shows that responsiveness to received care cannot always be taken for granted. The narrative demonstrates that to promote health in older people living in the community, professionals should also consider the qualities, skills, motivations and aspirations of older people when designing interventions aimed at improving (older) people's health. The assumption of this salutogenic approach is that the individual will be receptive to engaging in the promotion of their health and that their motivation can be enhanced if issues that are important to their lives are identified [40].

It is therefore important for professionals to reflect on their own care practice, keep looking at what can be improved, have a dialogue with older people and listen carefully to their perspective.

Our study also showed that health promotion for older people in a vulnerable position and coping with age-related changes in life is a complex matter. To create 
wellbeing in older people, professionals should not only focus on avoiding or reducing risk factors to create a safe environment, but also on the quality of life and wellbeing of an older person. This can be done by taking account of the way older people endow meaning to the demanding circumstances they find themselves in (comprehensibility), their perceived feelings of control (manageability), and their motivation to comprehend and manage events (meaningfulness).

We hope that counter-stories like Mrs Jansen's help to lead to a deeper understanding of how health and social care professionals and older people think and act. We hope it contributes towards evaluating and improving the care practice for older people living in the community.

Acknowledgments The authors wish to thank all the older people who shared their experiences and welcomed us into their homes. We are particularly grateful to Mrs Jansen and her professionals who approved the publication of her narrative. We are also grateful for the healthcare professionals who helped recruit the participants for this study.

Open Access This article is distributed under the terms of the Creative Commons Attribution Noncommercial License which permits any noncommercial use, distribution, and reproduction in any medium, provided the original author(s) and source are credited.

\section{References}

1. Abma, T. A., \& Noordegraaf, M. (2003). Public managers amidst ambiguity: Towards a typology of evaluative practices in public management. Evalution, 9(3), 285-306.

2. Abma, T. A., \& Stake, R. E. (2001). Stake's responsive evaluation. New Directions for Evaluation, 92(4), 7-23.

3. Abma, T., Oeseburg, B., Widdershoven, G., Goldsteen, M., \& Verkerk, M. (2005). Two women with multiple sclerosis and their caregivers: Conflicting normative expectations. Nursing Ethics, 12(5), 479-492.

4. Abma, T., Molewijk, B., \& Widdershoven, G. (2009). Good care in ongoing dialogue. Improving the quality of care through moral deliberation and responsive evaluation. Health Care Analysis, 17(3), 217-235.

5. Abma, T., Bruijn, A., Kardol, T., Schols, J., \& Widdershoven, G. (2011). Responsibilities in elderly care: Mr. Powell's narrative of duty and relations. Bioethics.

6. Antonovsky, A. (1987). Unraveling the mystery of health: How people manage stress and stay well. San Francisco: Jossey-Bass Publishers.

7. Antonovsky, A. (1990). Salutogenesis; studying health vs studying disease. Paper presented at the Congress for Clinical Psychology and Psychotherapy.

8. Antonovsky, A. (1996). The salutogenic model as a theory to guide health promotion. Health Promotion International, 11(1), 11-18.

9. Becker, C. M., Glascoff, M. A., \& Felts, W. M. (2010). Salutogenesis 30 years later: Where do we go from here? International Electronic Journal of Health Education, 13, 25-32.

10. Billings, J., \& Leichsenring, (2005). Integrating health and social care services for older persons: Evidence from nine European countries. Vienna: Aldershot [etc.] : Ashgate.

11. Cattan, M., White, M., Bond, J., \& Learmouth, A. (2005). Preventing social isolation and loneliness among older people: A systematic review of health promotion interventions. Ageing \& Society, 25(1), 41-67.

12. Ciairano, S., Rabaglietti, E., De Martini, R., \& Giletta, M. (2008). Older people's sense of coherence: Relationships with education, former occupation and living arrangements. Ageing \& Society, 28, 1075-1091.

13. De Bakker, D. H., \& Groenewegen, P. P. (2009). Primary care in the Netherlands: Current situation and trends. Italian Journal of Public Health, 7(2), 128-135. 
14. De Boer, A. (2006). Rapportage ouderen. Veranderingen in de leefsituatie en levensloop. Den Haag: SCP.

15. Ewles, L., \& Simnett, I. (2003). Promoting health; a practical guide (5th ed.). London: Bailliere Tindall Elsevier Limited.

16. Ferri, C. P., Prince, M., Brayne, C., Brodaty, H., Fratiglioni, L., Ganguli, M., et al. for Alzheimer's Disease International. (2005). Global prevalence of dementia: A Delphi consensus study. Lancet, 366(2112-2117).

17. Forbes, D. A. (2001). Enhancing mastery and sense of coherence: Important determinants of health in older adults. Geriatric Nursing, 22(1), 29-32.

18. Gaymu, J., Ekamper, P., \& Beets, G. (2008). Future trends in health and marital status: Effects on the structure of living arrangements of older Europeans in 2030. European Journal of Ageing, 5, 5-17.

19. Gobbens, R. J. J., Luijkx, K.G., Wijnen-Sponselee, M.T., \& Schols, J.M.G.A. (2007). Fragiele ouderen: De identificatie van een risicovolle populatie. (Frail elderly. Identification of a population at risk). Tijdschrift voor Gerontologie en Geriatrie.

20. Greene, J. C., Kreider, H., \& Mayer, E. (2005). Combining qualitative and quantitative methods in social inquiry. In B. Somekh \& C. Lewin (Eds.), Research methods in the social sciences (pp. 274-281). London: Sage.

21. Harrop, E., Addis, S., Elliot, E., \& Williams, G. (2006). Resilience, coping and salutogenic approaches to maintaining and generating health: A review. Cardiff: Cardiff Institute of society, health and ethics.

22. Janssen, B., van Regenmortel, T., \& Abma, T. A. (2011). Identifying sources of strength: Resilience from the perspective of older people receiving long-term community care. European Journal of Ageing, 8(3), 145-156.

23. Kickbusch, I. (1996). Tribute to Aaron Antonovsky; What creates health. Health promotion international, 11(1), 5-6.

24. Laurant, M. G. H., Hermens, P. M. G., Braspenning, J. C. C., Sibbald, B., \& Grol, R. P. T. M. (2004). Impact of nurse practitioners on workload of general practitioners: Randomized controlled trial. British Medical Journal, 328, 927-930.

25. Laurant, M. G. H., Hermens, P. M. G., Braspenning, J. C. C., Akkermans, R. P., Sibbald, B., \& Grol, R. P. T. M. (2008). An overview of patients' preferences for, and satisfaction with, care provided by general practitioners and nurse practitioners. Journal of Clinical Nursing, 17, 2690-2698.

26. Lincoln, Y. S., \& Guba, E. G. (1985). Naturalistic inquiry. Beverly Hills: Sage.

27. Meadows, L. M., \& Morse, J. M. (2001). Constructing evidence within a qualitative project. In J. M. Morse, J. M. Swanson, \& A. J. Kuzel (Eds.), The nature of qualitative evidence. Thousand Oaks: Sage.

28. Morgan, A., \& Ziglio, E. (2007). Revitalising the evidence base for public health: An assets model. Promotion \& Education, supplement 2, 14(17), 17-22.

29. Riessman, C. K. (2001). Analysis of personal narratives. In J. A. Holstein \& J. F. Gubrium (Eds.), Handbook of interviewing. Thousand Oaks: Sage Publications.

30. Riessman, C. K. (2003). Narrative analysis. In M. S. Lewis-Beck, A. Bryman, \& T. Futing Liao (Ed.), The Sage encyclopedia of social science research methods, vol. 3. Thousand Oaks: Sage.

31. Saleebey, D. (1996). The strengths perspective in social work practice: Extensions and cautions. Social Work, 41(3), 296-305.

32. SCP. (2004). Zorg en wonen voor kwetsbare ouderen. Rapportage ouderen. SCP.

33. Stake, R. E. (2005). Qualitative case studies. In N. K. Denzin \& Y. S. Lincoln (Eds.), The Sage handbook of qualitative research (Vol. 3, pp. 443-466). Thousand Oaks, CA: Sage Publications Inc.

34. Sullivan, P. W. (1992). Reclaiming the community: The strengths perspective and deinstitutionalization. Social Work, 37(3), 204-209.

35. Tengland, P.-A. (2010). Health promotion and disease prevention: Logically different conceptions? Health Care Analysis, 18, 323-341.

36. Tengland, P.-A. (2010). Health promotion or risk prevention: A real difference for public health practice? Health Care Analysis, 18, 203-221.

37. Tronto, J. C. (1993). Moral boundaries. Political argument for an ethic of care. New York: Routledge.

38. Tronto, J. C. (2001). An ethic of care. In M. B. Holstein \& P. B. Mitzen (Eds.), Ethics in community based elder care. New York: Springer. American Society on Aging. 
39. Van Regenmortel, T. (2002). Empowerment en maatzorg. Een krachtgerichte, psychologische kijk op armoede. [Empowerment and tailored care. A strength based psychological approach to poverty]. Leuven/Leusden: Acco.

40. Whiting, L., \& Miller, S. (2009). Traditional, alternative and innovative approaches to health promotion for children and young people. Paediatric Nursing, 21(2), 45-50.

41. WHO. (1986, 2006). The Ottawa Charter for health promotion. Paper presented at the Ottawa charter for Health Promotion. First international Conference on Health Promotion, Geneva.

42. WHO. (2002). Active ageing. A policy framework. Madrid: World Health Organization.

43. Wiesmann, U., \& Hannich, H. J. (2008). A salutogenic view on subjective well-being in active elderly. Ageing \& Mental Health, 12(1), 56-65.

44. Windle, G., \& Woods, R. T. (2004). Variations in subjective wellbeing: The mediating role of a psychological resource. Ageing \& Society, 24, 583-602.

45. Wuite, J., Greweldinger-Beudebeker, M. C., Abrahamse, G., \& Maes, J. A. M. B. (2008). Een voorstel voor zorginnovatie bij ouderen in een kwetsbare positie. [A proposal for care innovation for older people in a vulnerable position]. Heerlen: ANBO, KBO, PCOB, Huis voor de Zorg.

46. ZonMW. (2008). Nationaal programma ouderenzorg 2008-2011. Den Haag: ZonMw. 